\title{
Complementing theoretical biochemistry with the uso of computer aids
}

\author{
Herrera, R., Moya-León MA. \\ Instituto de Biología Vegetal y Biotecnología, Universidad de Talca, 2 Norte 685 Talca \\ Chile (raherre@utalca.cl)
}

Teaching biochemistry in the current state of science and society requires a special motivation for learning, especially for students where Biochemistry is one of the courses on their careers. The traditional way of teaching, based on the teacher-student relationship, mostly unidirectional, does not fulfil the needs imposed in this era. Considering the current situation, University students require new abilities in their training and the use of computers can be a facility for discovering and research, enabling the experience of new and diverse situations. The design of teaching material for undergraduate students who take biochemistry as complementary course should be seen as an opportunity to complement theoretical aspect on the current courses. We have used three different approaches: (I) Modelling proteins indicating key motifs at the three-dimensional structure and residues where inhibitors can be attach. (II) Generation of activities by the use of sensors. And (III) elaborating active quizzes where students can be drive on their learning. Building knowledge based on practical experience can improve student's competence on basic science and the learning process can be complemented in the use of dynamics models. 
This document was created with Win2PDF available at http://www.win2pdf.com. The unregistered version of Win2PDF is for evaluation or non-commercial use only. This page will not be added after purchasing Win2PDF. 